\title{
Influence of Inoculation Method and Spawn Level on Biological Efficiency of Pleurotus ostreatus
}

\author{
${ }^{* 1}$ IDOWU, OO; ${ }^{2}$ KADIRI, M. ${ }^{1}$ OTUNLA, CA \\ Vegetable Research Programme, National Horticultural Research Institute, Idi-Ishin, Ibadan \\ Dept. of Botany, University of Agriculture, Abeokuta \\ funmilayoidowu@yahoo.com; mukailakadiri@yahoo.co.uk; calebotunla@gmail.com
}

\begin{abstract}
Pleurotus ostreatus, an edible mushroom cultivated worldwide and appreciated due to its exotic taste and nutritional value. Spawning rate and method of spawn application are crucial factors influencing mushroom growth and yield. The objective of this work was to determine the effect of spawn quantity and spawning techniques on the growth and yield of $P$. ostreatus. It investigated the use of different spawning methods (on-spot, top and bottom, mixin and layering) and spawn levels $(3,5,7,9,11$, and 13\%) on the mushroom. The results obtained showed that as the spawn level increased, growth and yield parameters also increased. The highest number of fruits $(11.33)$, fruit weight $(65.69 \mathrm{~g})$, widest pileus $(657 \mathrm{~cm}$.) and longest stipe $(5.53 \mathrm{~cm})$ were observed at $13 \%$ spawn level and least in others. The densest mycelia were obtained as from 9\% spawn levels; the mean fruit weight was highest $(7.56 \mathrm{~g})$ at $9 \%$. Significantly shortest days to substrate colonization and primodia initiation were observed at $13 \%$ spawn level and the longest at 3\%. The results for spawning methods indicated highest biological efficiency (62.57\%) when spawn was applied at both ends of the bag while the least was on the on-spot application. Days to substrate colonization and initiation of the mushroom primodia were shorter significantly at $\mathrm{p}<0.05$. This findings implied that when sufficient amount of spawn is added to a fruiting substrate and applied bi-directionally, the mycelium grows faster and has more energy available for fruiting body formation, hence the increased yield and better biological efficiency. (O JASEM
\end{abstract}

http://dx.doi.org/10.4314/jasem.v20i3.7

KEY WORDS: Spawning method, spawn level, Pleurotus ostreatus, biological efficiency

Mushroom are fungi with distinct fruiting bodies which are fleshy in nature. They belong to the family Agaricales and the class Ascomycetes or Basidiomycetes depending on how their spores are borne (Ingold, 1979). Mushrooms are saprophytes living on dead organic matter, they produce extracellular enzymes from their actively growing mycelia which digest the lignocellulosic content of the medium on which they are growing and in turn absorb the digested substance into their system (Oei, 1991).

Mushrooms also serve as delicacies in different parts of the world because of their exotic taste and nutritional qualities. They can be grown on various agro-industrial wastes using different technologies; they convert the materials into protein-rich food that is suitable for other uses. In Nigeria, mushrooms have been used as substitute for meat especially among the rural poor and their supply is usually from the wild. With urbanization, many of these wild mushrooms are disappearing and are becoming scarce and the only alternative to ensuring supply of these mushrooms is by domesticating them and ensuring high yield.
Pleurotus ostreatus, popularly known as abalone or oyster mushroom grows under natural condition on dead woody branches of trees as a saprophyte and primary decomposer. It can be grown successfully under controlled and semi-controlled conditions using various agro-industrial wastes and is popularly grown all over the world especially in the tropical and sub-tropical regions. P. ostreatus is reputed to be antitumoral because of its content of lovastatin, a chemical compound known to inhibit the growth of tumor (Rambelli and Menini, 1985). They constitute the second largest mushroom variety produced in the world (Mshandete, 2008).

Spawn is the mushroom mycelium that has fully colonized a steam sterilized substrate that is used to 'seed' the final fruiting substrate. It serves as the planting material in mushroom cultivation (Romaine et al, 2007). The quantity of spawn used does not directly affect the yield of mushrooms (Quimio et al, 1990). However the use of more spawn has been found to influence mushroom growth, development and yield. Spawning is the inoculation of the mushroom culture into the substrate or compost 
which is the actual planting of the spawn. This present study was undertaken to evaluate the effect of spawn quantities and spawning techniques on the growth and yield of $P$. ostreatus an edible mushroom.

\section{MATERIALS AND METHOD}

Fresh and young fruiting body of $P$. ostreatus was obtained from the Mushroom Production Unit of the Vegetable Research programme of National Horticultural Research Institute, Ibadan Nigeria. The pure culture of the mushroom was prepared by tissue culture, maintained on potato dextrose agar and stored in a refrigerator until needed. Planting spawn of the mushroom being studied was prepared from the culture generated above according to the method described by Peng et al, (2000).

Sawdust of Gmelina aborea was collected from Forestry Research Institute of Nigeria, Ibadan and was used as the basal substrate which was mixed with rice bran $(20 \%)$ and calcium carbonate $(1 \%)$ to adjust the $\mathrm{pH}$. The mixture was moistened with water and left overnight to allow the water to permeate the substrate particles. The previously moistened substrate was pressed against the palm of the hand to be sure that the water was not in excess to allow for the mycelia growth. The mixture was then weighed (300g) into polyethylene bags held in place with cut polyvinylchloride pipe $(2.5 \mathrm{~cm}$ diameter $)$, plugged with cotton wool and covered with aluminium foil and sterilized at $121^{\circ} \mathrm{C}$ for 30 mins, allowed to cool down to room temperature and inoculated with the spawn prepared above at 3, 5, 7, 9, 11 and $13 \%$ rate. The bags were incubated for 4 weeks at room temperature.

The experiment was a completely randomized design with each treatment replicated 6 times. After incubation, the substrate bags were weighed and moved to the cropping house. The bags were opened, wetted and left for the appearance of the mushroom primodia. The mushroom fruiting bodies from each bag were harvested and weighed for the calculation of the biological efficiency (ratio of fresh mushroom harvested to substrate dry weight x 100) (Royse et al, 2004).

Other data collected were days taken by the mushroom mycelium to colonize the substrate from the date of spawning (fcol), days to primodial initiation (ini) (time taken for the formation of the pinhead from the date of spawning), number of fruits/ bag, total fruit weight, mean fruit weight, width of pileus, length of stipe and mycelia density. The mycelia density was evaluated visually using the method of Fasidi (1995) slightly modified by Idowu, (2009) on a scale of +1 to +4 (highest mycelia density at+4 and the least at +1 ).

The mushroom spawn prepared above was also used to inoculate freshly harvested rice straw collected at the International Institute for Tropical Agriculture, Ibadan. This was chopped into small sizes of about 3$5 \mathrm{~cm}$ for ease of bagging and soaked overnight and drained the following morning. The substrate $\mathrm{pH}$ was adjusted (6.5) by adding $1 \%$ calcium carbonate, weighed and packed as above (200g/bag) and sterilized in an autoclave at $121^{\circ} \mathrm{C}$ for 30 minutes. After cooling $(30 \pm 2)$, the bags were inoculated differently with $20 \mathrm{~g}$ each of spawn of P. ostrearus, using the following methods, on-spotl (spawn applied at the top), mix-in (spawn was thoroughly mixed into the substrate), layering (spawn was sandwiched in between substrate layers) and top and bottom (spawn was applied at both top and bottom ends of the bag).

The experimental design was as above. The inoculated bags were kept in an incubation room for 4weeks, weighed and moved to the cropping house with the bags cut-opened and moistened to allow for the mushroom primodia to emerge. The mushroom carpophores were harvested after about 4-5days after opening of the bags. The harvesting was done as the mushrooms appeared.

Days to substrate colonization and time of primodia initiation were noted. The morphological data such as number of fruits, pileus width, length of stipe, average fruit weight and total fruit weight were collected and the biological efficiency was calculated as above.

\section{RESULTS AND DISCUSSION}

Number of days to substrate colonization and the appearance of mushroom primodia (pinheads) decreased with increase in the level of spawn applied Fig 1. The shortest days to substrate colonization and primodial initiation were at $13 \%$ (19.67 and32.00 )and the longest was at 3\% (30.33 and 38.33) spawn quantity. This agrees with the findings of Bhatti et al, 2007 and Royse et al, (2004) who reported reduction in days to substrate colonization, primodial inititiation and increase in the yield of some Pleurotus spp as a result of increase in spawn rate. The increase in the quantity of the spawn may reduce the effect of competitive organisms present in the fruiting substrate, as a result, the growth of competitor organisms in the substrate is hindered and 
yield will be regular and not affected by this competition (Quimio et al, 1990 and Stamets, 2000).

All the growth characters studied (number of fruits,total fruit weight, mean fruit weight, width of pileus, lenght of stipe and mycelium density) responded differently to the various spawn levels evaluated with significantly higest growth values at $13 \%(\mathrm{p}<0.05)($ Table 1$)$.

All the spawning methods studied resulted into colonization of the substrate. The mushroom had its shortest colonization and primodial initiation periods on the top and bottom (bidirectional method) spawning method while the longest periods were on the topical method, (Fig 3).

The various inoculation methods employed to evaluate their effects on the yield of $P$. ostreatus influenced its biological efficiency which was highest when the top and bottom method of spawning was applied, with the least occuring on the topical spawning method (Fig 4).

The shortest spawn running time obtained when the spawn was bi- directionally applied resulted in significantly higher mushroom yield and greater biological efficiency $(\mathrm{p}<0.05)$. This result implies that when spawn is applied on both ends of the substrate bags, the mushroom mycelium grows faster and has more energy available for fruiting body production, hence the increased yield and better biological efficiency. In conclusion, increasing the spawn quantity from 9 to $11 \%$ and choosing the right spawning technique preferably top and bottom method or layering or sandwiching the spawn within the substrate may result in higher mushroom yield and fewer days to mushroom production which will in turn lower the cost of production and will ultimately lower the cost to consumers,

Table 1: Effect of different spawn quantity on growth and yield of IPleurotus ostreatus

\begin{tabular}{|c|c|c|c|c|c|c|c|c|}
\hline $\begin{array}{l}\text { Treatment } \\
\text { (spawn level } \\
(\%) \text { ) }\end{array}$ & $\begin{array}{l}\text { Number of } \\
\text { fruit/bag }\end{array}$ & $\begin{array}{l}\text { Fruit } \\
\text { weight } \\
(\mathrm{g}) / \mathrm{bag}\end{array}$ & $\begin{array}{l}\text { Width of } \\
\text { pileus }(\mathrm{cm})\end{array}$ & $\begin{array}{l}\text { Length of } \\
\text { stipe }(\mathrm{cm})\end{array}$ & $\begin{array}{l}\text { Mean fruit } \\
\text { weight } \\
\text { (g)/bag }\end{array}$ & $\begin{array}{l}\text { Days to substrate } \\
\text { colonization }\end{array}$ & $\begin{array}{l}\text { Days to } \\
\text { primodia } \\
\text { lnitiation }\end{array}$ & $\begin{array}{l}\text { Mycelia } \\
\text { density }\end{array}$ \\
\hline 3 & $5.67^{\mathrm{d}}$ & $30.7^{\mathrm{e}}$ & $4.1^{\mathrm{c}}$ & $3.2^{\mathrm{c}}$ & $5.46^{\mathrm{c}}$ & & & +1 \\
\hline 5 & $5.67^{\mathrm{d}}$ & $33.1^{\mathrm{d}}$ & $4.57^{\mathrm{bc}}$ & $3.22^{\mathrm{c}}$ & $5.89^{\mathrm{c}}$ & & & +1 \\
\hline 7 & $7.33^{\mathrm{c}}$ & $51.21^{\mathrm{c}}$ & $5.13^{\mathrm{b}}$ & $4.17^{\mathrm{b}}$ & $7.01^{\mathrm{b}}$ & & & +2 \\
\hline 9 & $8.33^{\mathrm{b}}$ & $62.78^{b}$ & $5.43^{\mathrm{b}}$ & $4.32^{\mathrm{b}}$ & $7.56^{\mathrm{a}}$ & & & +3 \\
\hline 11 & $11^{\mathrm{a}}$ & $64.87^{\mathrm{ab}}$ & $6.5^{\mathrm{a}}$ & $5.47^{\mathrm{a}}$ & $5.9^{\mathrm{c}}$ & & & +4 \\
\hline 13 & $11.33^{\mathrm{a}}$ & $65.69^{\mathrm{a}}$ & $6.57^{\mathrm{a}}$ & $5.53^{\mathrm{a}}$ & $5.81^{\mathrm{c}}$ & & & +4 \\
\hline
\end{tabular}

+1 =scanty mycelium, $+2=$ moderatemycelium, $+3=$ dense mycelium, +4 Verydense mycelium Means followed by the same superscript letter(s) in each column are not significantly different $(\mathrm{P}>0.05)$ according to DMRT.
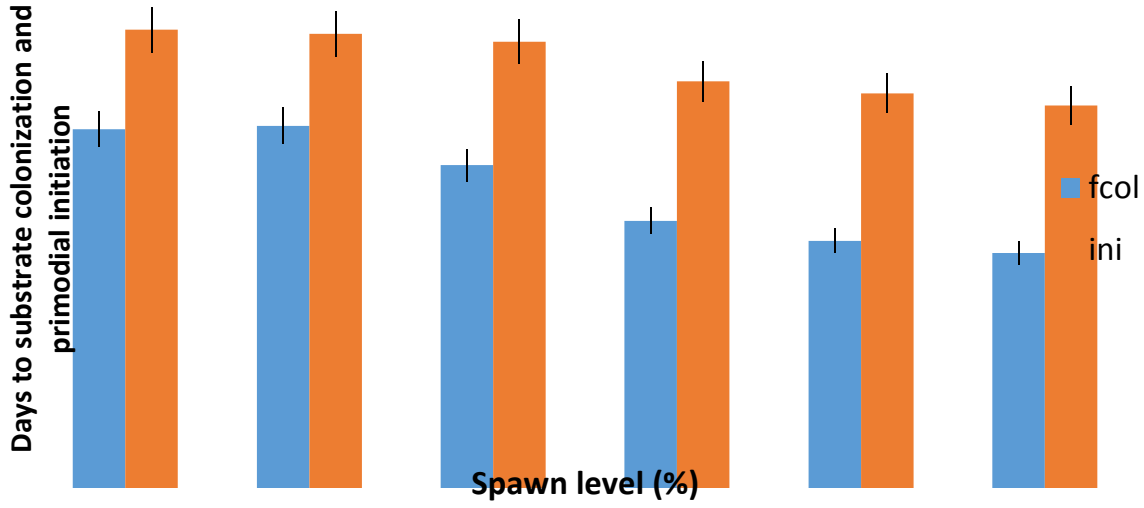

fcol = days to substrate colonization; ini = days to primodia initiation

Fig1: Effect of spawn quantity on days to substrate colonization and primodial initiation of $P$. ostreatus 

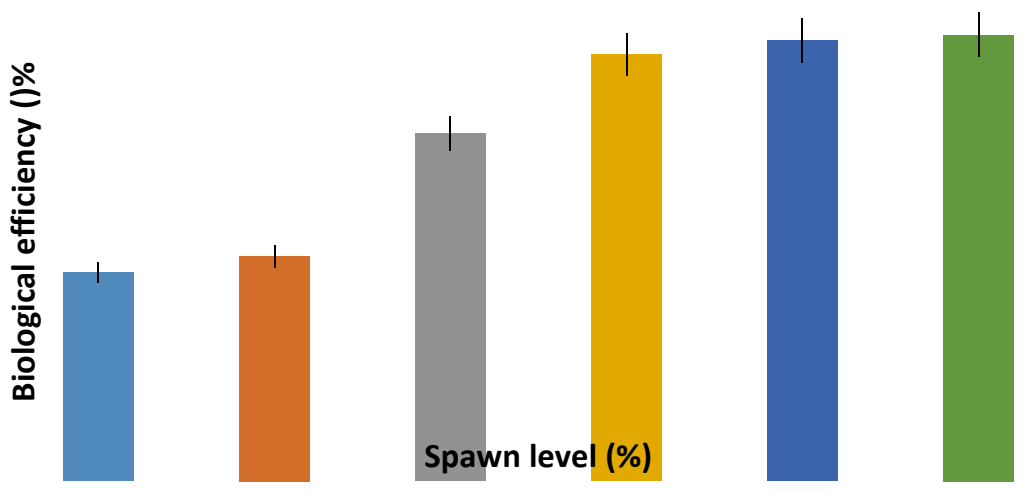

Fig 2: Effect of spawn quantity on the biological efficiency of $P$. ostreatus
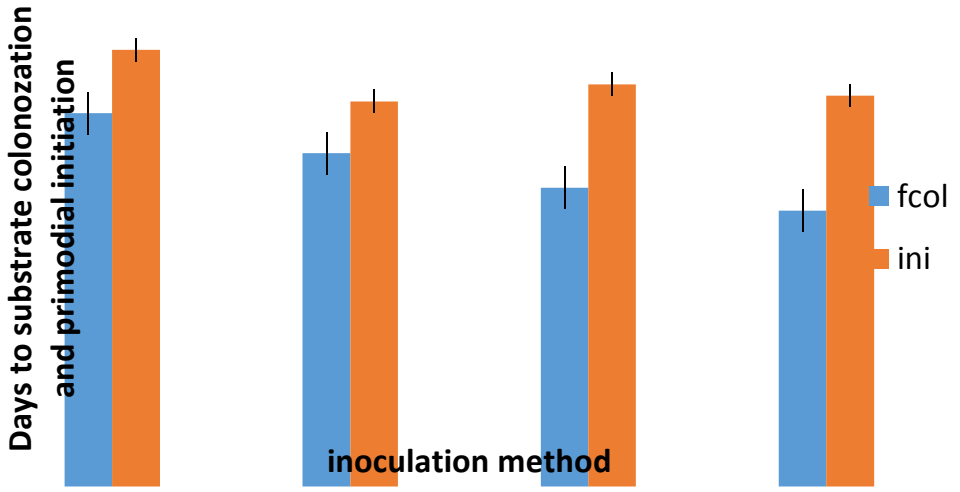

fcol $=$ days to substrate colonization; ini $=$ days to primodia initiation

Fig 3: Effect of inoculation technique on days to substrate colonization and primodial initiation of $P$. ostreatus
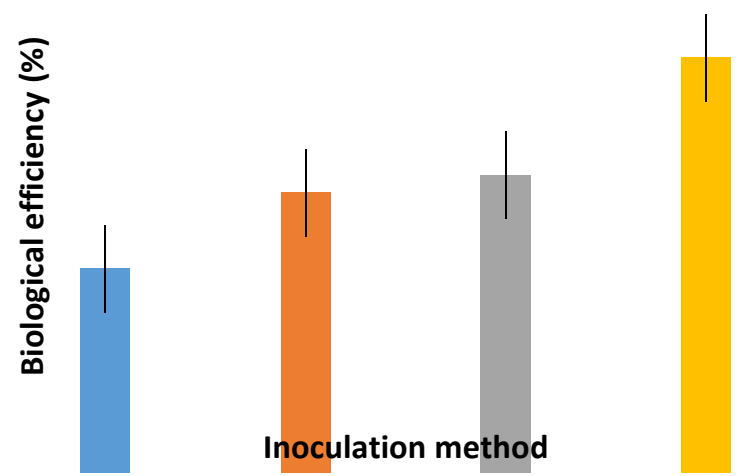

Fig 4: Effect of spawn inoculation technique on days to substrate colonization and primodial initiation of $P$. Ostreatus 


\section{REFERENCES}

.Bhatti, M.I., Jiskan,M.M., Wagan, K.H., Pathan, M.A. and Magsi, M.R. (2007). Growth, development and yield of oyster mushroom Pleurotus Ostreatus as affected by different spawn rates. Pak. J. Bot. 39(17):2685-2692.

Fasidi IO (1995). Studies on Volvariella esculenta (Mass) Singer: cultivation on agricultural wastes and proximate composition of stored mushrooms. Food Chemistry, 55: 161-163.

Idowu, OO and Kadiri M. (2009). Effects of cocoa shell supplementation on the production of two oyster mushrooms (Pleurotus pulmonarius and $P$. ostreatus). Advances in Science and Technology. Vol. 3(2), $146-149$.

Ingold, C. T. (1979). The Nature of Toadstools: Edward Arnold (Publishers)Limited: 41 Bedford Square, London pp. 1-44.

Mshandete, A.M. and Cuff, J. (2008). Cultivation of three types of indigenous mushroom: Coprinus cinereus, Pleurotus flabelatus and Volvariella volvaceae on composted Sisal decortication residue inTanzania. African Journal of Biotechnology Vol.7 (24), 4551 - 4562pp.

Oei, P. (1991). "Manual of mushroom cultivation techniques, species and opportunities for commercial cultivation in developing countries", CTA, 21-26.
Peng, J., Lee, C. and Tsai, Y. (2000).Effect of rice bran on the production of different king oyster mushroom strain s during bottle cultivation. Jour. Agric. Res. China. 49(3), 60-67

Quimio, T. H., Chang, S. T. and Royse, D. J. (1990) "Technical guidelines for mushroom growing in the tropics", FAO Plant Production and Protection Paper 106, pp 160-170.

Rambelli, A. and Menini, U.G. (1985).Manual on mushroom cultivation. FAO plant production and protection paper: $43-65$.

Romaine CP, Royse DJ, Schlagnhaufer C (2007) Imazalil sulfate as an alternative spawn and supplement treatment for green mold disease. Mushroom News 55(4):4-7.

Royse, D.J., Rhodes, T.W., Ohga, S. and Sanchez, J.E. (2004). Yield, mushroom size and time to production of Pleurotus cornucopiae (oyster mushroom) grown on switch grass substrate, spawned and supplemented at various rates. Bioresour. Technol., 91: 85-91.

Stamets, P.. (2000,). Materials for formulating fruiting substrates. In Growing Gourmet and Medicinal Mushrooms, 3rdedition. Ten Speed Press,Berkeley, Toronto, $140-180$. 